\title{
Effect of Antimony on the Tensile Strength and the Morphology of Si Platelets in Recycled Aluminum Piston Alloys
}

Durowoju MO*, Babatunde IA, Raheem WA and Ajala MT

Department of Mechanical Engineering, Ladoke Akintola University of Technology, Ogbomosho, Nigeria

*Corresponding author: Durowoju MO, Department of Mechanical Engineering, Ladoke Akintola University of Technology, Ogbomosho, Nigeria, Tel: +2348032070449;

E-mail: modurowoju@lautech.edu.ng

Rec date: Mar 13, 2014; Acc date: May 07, 2014; Pub date: May 15, 2014

Copyright: (C) 2014 Durowoju MO, et al. This is an open-access article distributed under the terms of the Creative Commons Attribution License, which permits unrestricted use, distribution, and reproduction in any medium, provided the original author and source are credited.

\begin{abstract}
Recycled AISi2.4Mg cast alloys can be used directly in new cast products such as textile machinery parts and for structural engineering such as aluminum sidings and window frames. In this work, the modification effect of antimony $(\mathrm{Sb})$ on the microstructure and tensile strength of recycled AISi2.4Mg cast alloy was systematically investigated. Aluminum Piston scraps was melted in a furnace to form a melt composition. The melt was adjusted to form the present composition, consisting essentially of 2, 4, 6, 8, 10 and $12 \mathrm{gr}$ addition of Sb. However, its effect as a modifier is more pronounce at $8 \mathrm{gr}$ addition of $\mathrm{Sb}$ and caused refinement of microstructure, which led to increase in mechanical properties. It was obvious that Sb modify the coarse Si platelets into a more fibrous one. An optimal tensile strength of $82.59 \mathrm{MN} / \mathrm{m}^{2}$ was obtained.

However, fractal analysis performed on the micrograph revealed that the formation and features of Si platelets in as-cast sample and samples treated with 2 to $4 \mathrm{gr}$ of Sb can act as a seedbed for micro-crack initiation because of their irregularity in nature and their departure from perfect shape. The best platelet shape was observed in $8 \mathrm{gr}$ addition of $\mathrm{Sb}$ having a weighted average value of fractal dimension $D=0.5961$ and sphericity $\beta=0.8501$ respectively.
\end{abstract}

Keywords: Recycled AlSi2.4Mg alloy; Fractal analysis; Modifier; Si platelets

\section{Introduction}

Molten recycled aluminum contains various kinds of indigenous inclusions $\left(\mathrm{Al}_{2} \mathrm{O}_{3}, \mathrm{MgAl}_{2} \mathrm{O}_{4}, \mathrm{TiB}_{2}\right.$ and nitrides), sludge, dissolved hydrogen and light metal impurities. To ensure the removal of impurities from the melt, various methods have been adopted by researchers such as the principles of sedimentation, flotation or electromagnetic forces. Others focus on the uses of modifiers and grain refinements. Farkašová et al. [1] revealed that antimony is predominantly used in Europe and Japan, and is commonly referred to as a permanent modifier and does not require any make up addition at the foundry. Antimony has the advantage of modifying the grain structure of cast aluminum alloy simply because it does not fade, not sensitive to regassing and suitable for parts which are prone to porosity formation [2-4]. Better quantitative understanding of the microstructure property relationships in cast aluminum alloys coupled with improved foundry practice will allow wider application of reliable castings in mass production. Therefore, careful study of features, formation and distribution of platelets in cast aluminum base alloys is expected to yield improved mechanical properties so as to meet various challenges in manufacturing industries.

A few researchers including Paraskevas et al. [5], Alwan et al. [6] and Bolden et al. [7] revealed that most aluminum scraps were examined based on their expected mean compositional values and considered to be discarded either from; castings used in engines and transmissions from vehicles, or wrought products from automobiles, wire and cable scraps, used beverage cans (UBC) and from a single alloy Al-6061. Literature sources revealed that pistons were generally made of Al-Si-based alloy. According to Fintova et al. [8], Hurtalová et al. [9], and Kósa et al. [10], eutectic or hypereutectic aluminum cast alloys especially the Al-Si-base alloys belong to materials used in automotive industry for engine parts including piston and cylinder heads. As target alloys in the case studies several Al-Si-based alloys have been examined, among which are the recycling of aluminum 7075 scrap and Al-356 alloy [1,3,11]. These alloys after recycling were used for other engineering applications.

However, fractal analysis is widely used to quantify the selfsimilarity and complexity of natural structures such as the perimeters of clouds, coastlines and various other geometries [12]. Devesh et al. [13] and Durowoju et al. [14] applied it in engineering field to study the morphological changes in pores found in cast alloys. Hangai and Kitahara [12] applied it in the field of medicine to distinguish cancer tissue from normal tissue. However, for irregular microstructures, the application of fractal geometry offers a method by which both the individual particle, shape and the mode of the distribution of the particles can be fully described in a numerical manner [15]. The use of fractal analysis to study surfaces of different materials has been done by many researchers and it is still receiving increasing attention. Hangai and Kitahara [12], and Durowoju et al. [14] revealed that fractal analysis of the pores in the microstructure of cast aluminum alloys provided information linking their composition and processing to the crack initiation and the quantitative estimation of the morphology of pores such as their shape, size or distribution which can also be a source of useful information. Hangai and Kitahara [12] studied the quantitative evaluation of porosity in aluminum die castings by fractal analysis of perimeter while Durowoju and Akintan [16] investigated the variation between fractal geometry and 
Page 2 of 6

mechanical properties of aluminum alloys containing $\mathrm{Cu}, \mathrm{Si}, \mathrm{Mg}$ and $\mathrm{Zn}$ (\%wt) under different heat treatments. Kong et al. studied the microstructural feature and fractal dimension of powder aggregates of $\mathrm{Fe}-2 \% \mathrm{Cu}-0.5 \% \mathrm{C}$ compacted and sintered under varying temperature.

\begin{tabular}{|l|l|}
\hline Materials Elements & AlSiMg \\
\hline $\mathrm{Si}$ & 13.68 \\
\hline $\mathrm{Cu}$ & 1.08 \\
\hline $\mathrm{Mn}$ & 0.197 \\
\hline $\mathrm{Mg}$ & $>2.40$ \\
\hline $\mathrm{Fe}$ & 0.35 \\
\hline $\mathrm{Zn}$ & 0.249 \\
\hline $\mathrm{Ni}$ & 0.62 \\
\hline $\mathrm{Pb}$ & 0.035 \\
\hline $\mathrm{Cr}$ & 0.016 \\
\hline $\mathrm{Ti}$ & 0.032 \\
\hline $\mathrm{Be}$ & $<0.0001$ \\
\hline $\mathrm{Bi}$ & $<0.001$ \\
\hline $\mathrm{Ca}$ & 0.0004 \\
\hline $\mathrm{Sn}$ & 0.01 \\
\hline $\mathrm{Co}$ & $<0.001$ \\
\hline $\mathrm{Na}$ & $<0.0001$ \\
\hline $\mathrm{P}$ & 0.001 \\
\hline $\mathrm{Sr}$ & 0.0001 \\
\hline $\mathrm{V}$ & 0.014 \\
\hline $\mathrm{Zr}$ & 0.0026 \\
\hline $\mathrm{Cd}$ & 0.0012 \\
\hline $\mathrm{Al}$ & balance \\
\hline
\end{tabular}

Table 1: Chemical composition of alloy (wt\%)

Some complex microstructures defy description in terms of Euclidean principles. Fractal geometry can therefore be used to numerically characterize any shape or collection of shapes, however irregular and chaotic they may seem. For better understanding of the veracity of this method, this study therefore uses the fractal analysis to numerically characterize the Si platelets in recycled aluminum alloy (pistons scrap) and to identify the point where Si platelets can act as seedbed for crack initiation.

\section{Experimental Procedure}

\section{Recycled Al-Si-Mg cast alloy}

The major recycled pistons used in this work were those of motorcycles. Discarded pistons were collected from various automechanic workshops in Oyo state, Nigeria. Scrap aluminum pistons collected were washed and dried, before charging into the furnace. The recycled pistons were obtained in form of ingot. Compositional analysis performed via Mini 4 Spectrometry Table 1, revealed that eutectic recycled alloy obtained has a nominal composition $83.92 \% \mathrm{Al}$ $13.86 \mathrm{Si}$ and $2.4 \% \mathrm{Mg}$. However, 2 gr to 12 gr of antimony (Sb) were added to $150 \mathrm{gr}$ of aluminum ingot. The melting temperature was maintained at $700^{\circ} \mathrm{C} \pm 5^{\circ} \mathrm{C}$ for about 1 minute. The melt was gently stirred, skimmed before pouring into the prepared sand mould. Seven samples were prepared with as-cast alloy. The alloys were sand cast into cylindrical bars of $12 \mathrm{~mm}$ diameter, $200 \mathrm{~mm}$ length and machined into standard specifications for tensile testing using Monsanto Tensometer and following standard test procedures in accordance with the ASTM E8M-91 standards (1992). An optical metallurgical microscope XJL-17 model with magnification $10 \times 10$ was used for taken the micrograph of the samples. All the samples were grounded, polished and etched using $2 \% \mathrm{NaOH}$ solution.

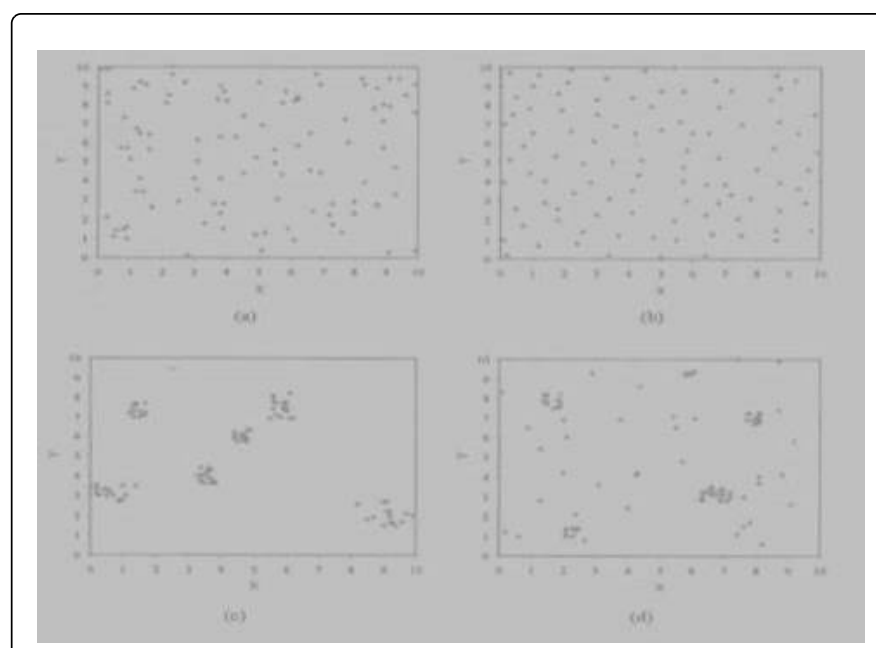

Figure 1: The four common types of spatial point patterns (a) random, (b) regular, (c) clustered, (d) clustered superimposed on random background.

\section{The fractal approach to platelets characterization}

Fractal geometry was firstly developed by Mandelbrot [17]. Its principle is universal in any measurement and has been previously used by many researchers to numerically describe complex microstructures including graphite flakes and nodules [18]. The mathematical basis for measuring chaotic objects with the power law is adopted in this work. The basic equation is as follows:

$$
\mathrm{P}=\mathrm{P}_{\mathrm{e}} \delta^{\mathrm{D}-1}\left(1<\mathrm{D}<2 \text { and } \delta_{\mathrm{m}}<\delta<\delta_{\mathrm{M}}\right)
$$

where $\mathrm{P}_{\mathrm{e}}$ is the measured perimeter, $\mathrm{P}$ is the true perimeter, $\delta$ is the yardstick, $\delta_{\mathrm{m}}$ and $\delta_{\mathrm{M}}$ are the upper and lower limits respectively for any shape and $\mathrm{D}$ is defined as the fractal dimension. The fractal dimension $\mathrm{D}$ describe the complexity of the contour of an object which can be more practically called roughness [19].

Sphericity $\beta$, on the other hand is used with fractal dimension $D$, to describe the shape of the pores formed [12]. It can be expressed as

$$
\beta=4 \pi \mathrm{AT} / \mathrm{P}^{2}(0<\beta<1 \text { and } 1<\mathrm{D}<2)
$$

From the above two equations:

$$
\beta=\left(4 \pi \mathrm{AT} / \mathrm{P}^{2}\right) \delta^{2(1-\mathrm{D})}(0<\beta<1 \text { and } 1<\mathrm{D}<2)
$$


Citation: Durowoju MO, Babatunde IA, Raheem WA, Ajala MT (2014) Effect of Antimony on the Tensile Strength and the Morphology of Si Platelets in Recycled Aluminum Piston Alloys. J Material Sci Eng 3: 137. doi:10.4172/2169-0022.1000137

Page 3 of 6

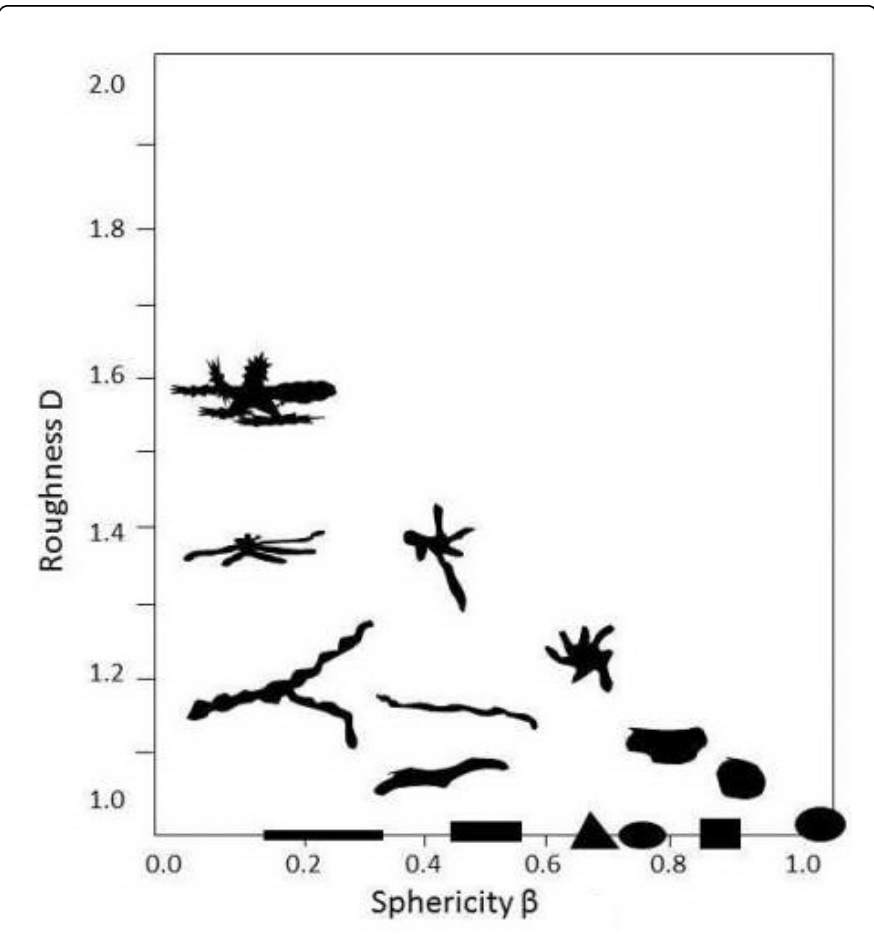

Figure 2: Illustration of development of irregular shapes based upon Euclidean circle or rectangle.

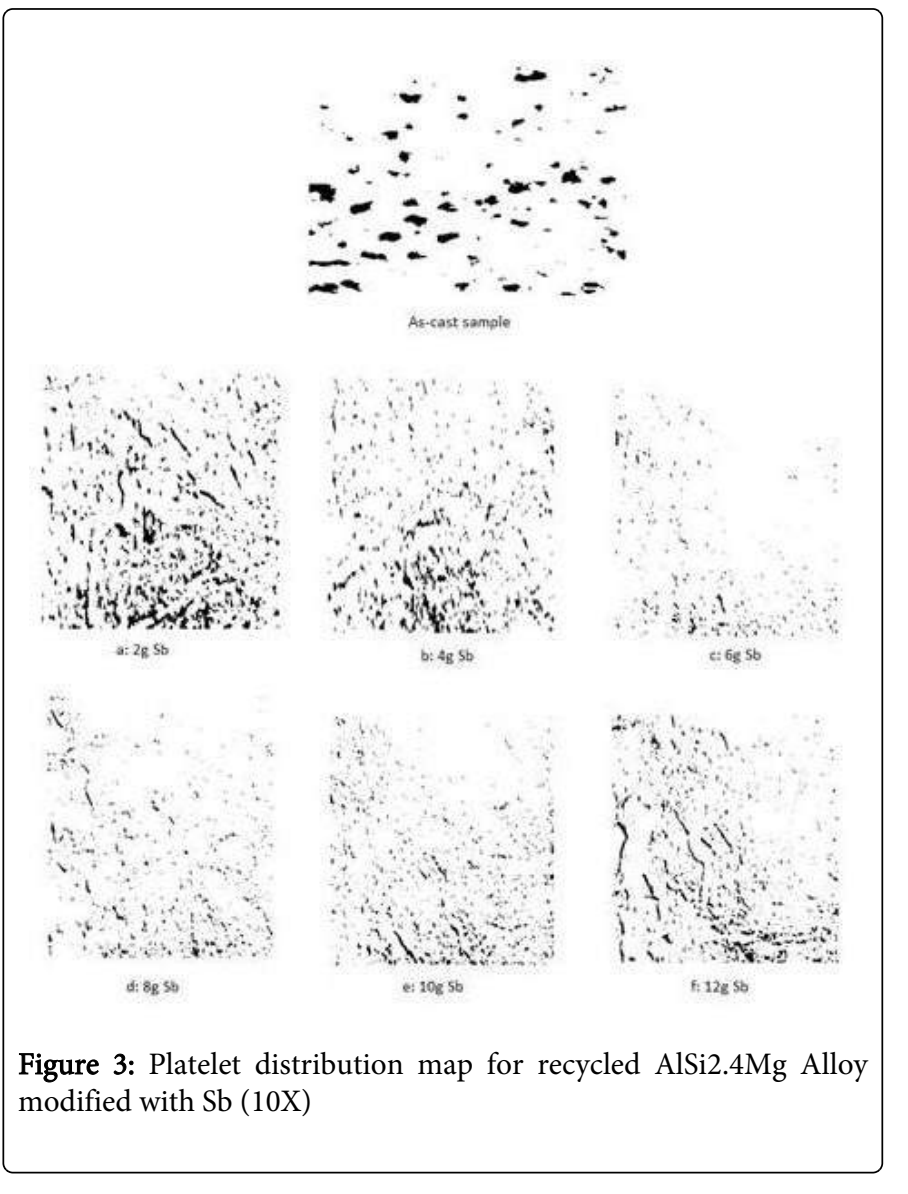

where AT is the total pore area. When $\beta=1$ and $D=1$, a perfect circular shape is formed by the pore in the microstructure. As $\beta$ decreases, the shapes become more elongated showing a departure from perfect sphere.

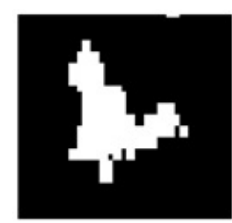

(a)

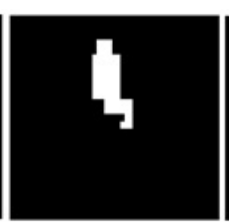

(b)

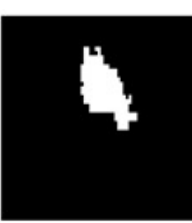

(c)

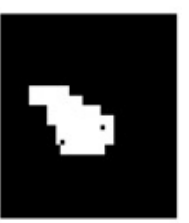

(d)
Figure 4: Isolation of silicon platelets in AlSi2.4M (a) as-cast (b-d) samples treated with $\mathrm{Sb}$

In this work, an interactive Matlab program was developed to obtain the numerical values of the fractal dimension $\mathrm{D}$ and the sphericity $\beta$. To develop the program the box counting method was used with a counter incorporated into the program and the small boxes or pixels occupied by the platelets outlines were counted. In all, four pixels $(2 \times 2$ pixels, $4 \times 4$ pixels, $8 \times 8$ pixels and $16 \times 16$ pixels $)$ and four grid sizes $(200 \times 200,100 \times 100,50 \times 50$ and $25 \times 25)$ were selected. The selections were made for better resolution and to obtain accurate values.

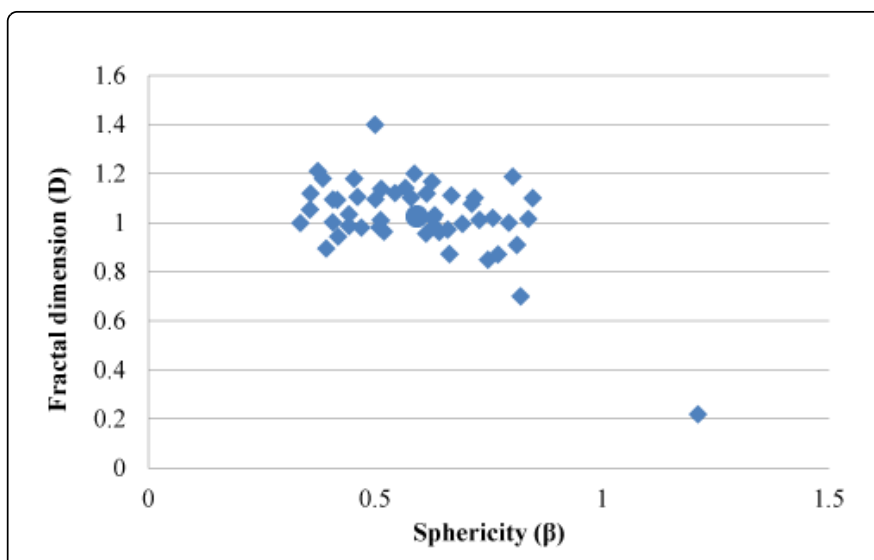

Figure 5: Platelet distribution map for As-cast recycled AlSi2.4Mg Alloy

The Spatial Point Pattern Method (Figure 1) and the platelets distribution map (Figure 2) were used to describe the patterns displayed by the Si platelets and also to categorize them into random, regular, clustered and clustered with regular background. The platelets distribution map can be further used to identify the shapes of the platelets and their dispersion from regular shapes. The silicon platelets obtained from the micrographs were shown in Figure 3 while Figure 4 shows the isolation of some of the Si platelets.

\section{Result and Analysis}

The Si platelets shown in Figure 3 revealed that the platelets in ascast sample are bigger in sizes when compared with samples modified with antimony. Fractal analysis performed revealed that the shapes of the Si platelets were irregular in nature as shown in Figure 4. Addition 
Citation: Durowoju MO, Babatunde IA, Raheem WA, Ajala MT (2014) Effect of Antimony on the Tensile Strength and the Morphology of Si Platelets in Recycled Aluminum Piston Alloys. J Material Sci Eng 3: 137. doi:10.4172/2169-0022.1000137

Page 4 of 6

of $\mathrm{Sb}$ has therefore produced finer platelets. Figures 5-11 presented the platelet distribution maps of each of the microstructure as obtained from the fractal analysis. Each data point represents an individual platelet and the big-sized data point represents the weighted average of the platelets' sphericities and fractal dimensions respectively.

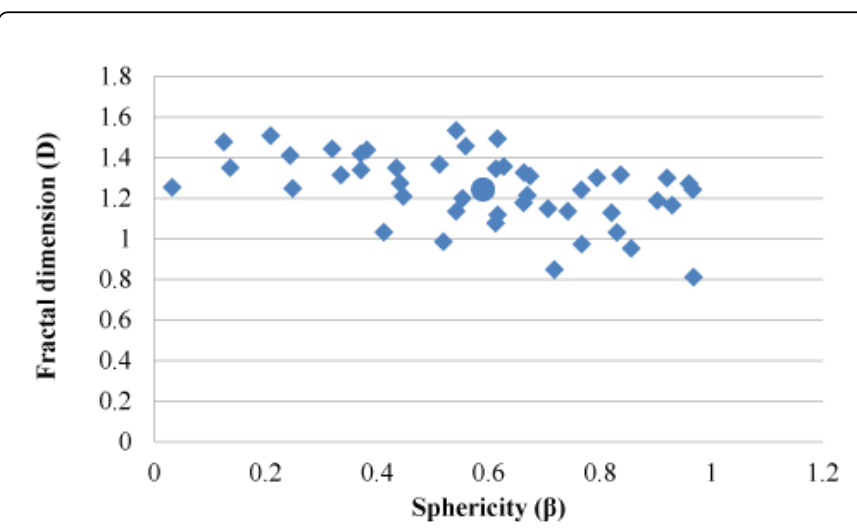

Figure 6: Platelet distribution map for recycled AlSi2.4Mg Alloy modified with $2 \mathrm{gr}$ of $\mathrm{Sb}$

Figure 5 shows the platelet distribution map for as-cast AlSi2.4Mg alloy prepared in sand mould. The weighted average values of 0.5914 and 1.0281 for sphericity and fractal dimension were obtained and the platelets were clustered. However, for sample treated with $2 \mathrm{gr}$ of $\mathrm{Sb}$ (Figure 6), the platelets had weighted average values 0.5917 and 1.2327 for sphericity and fractal dimension. The platelets were clustered with random background.

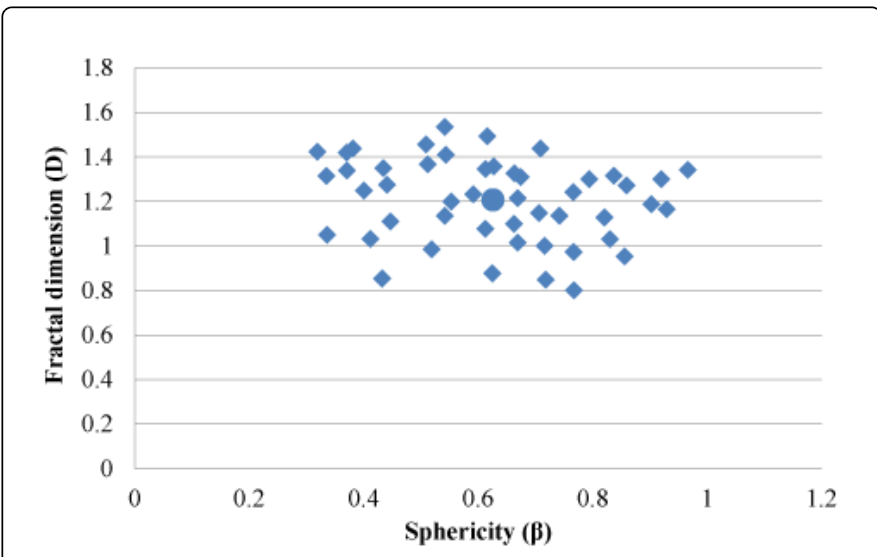

Figure 7: Platelet distribution map for recycled AlSi2.4Mg Alloy modified with $4 \mathrm{gr}$ of $\mathrm{Sb}$

Figures 7 and 8 show the platelet distribution maps for 4 gr and 6 gr addition of $\mathrm{Sb}$. In both cases the platelets were clustered on random background with weighted average sphericity values of 0.6259 and 0.6233 respectively, which is an indication that the platelets were attaining better regular shapes. This is evidence from the platelets distribution map.

Figure 9 shows the platelets distribution map for 8 gr addition of $\mathrm{Sb}$, with weighted average values of 0.5961 and 0.8501 for sphericity and fractal dimension respectively. The platelets were randomly distributed.

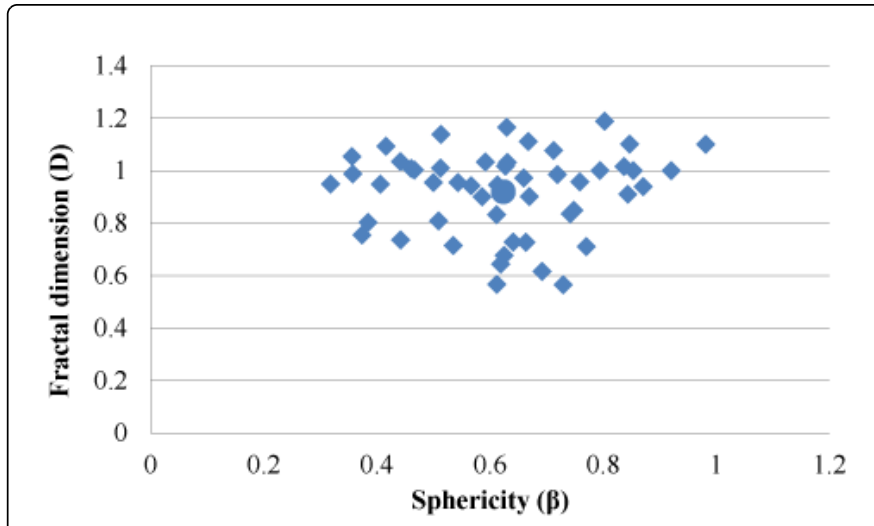

Figure 8: Platelet distribution map for recycled AlSi2.4Mg Alloy modified with $6 \mathrm{gr}$ of $\mathrm{Sb}$

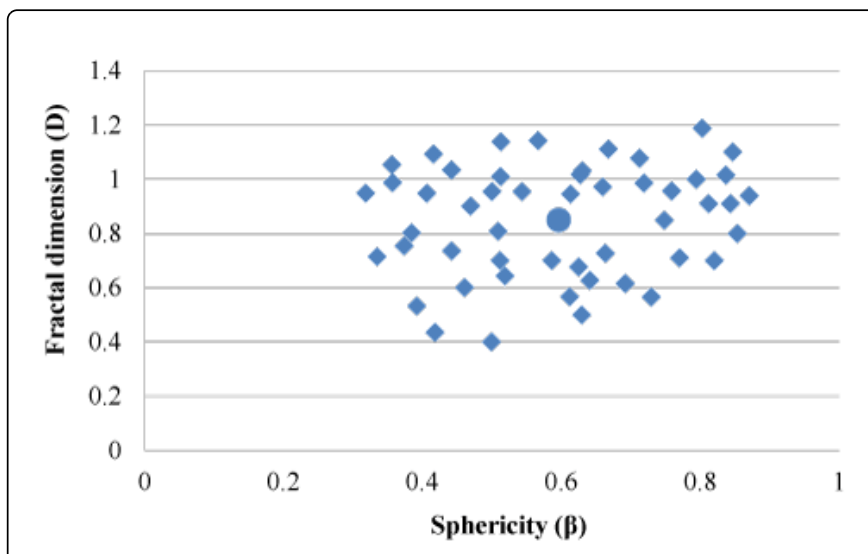

Figure 9: Platelet distribution map for recycled AlSi2.4Mg Alloy modified with 8 gr of $\mathrm{Sb}$

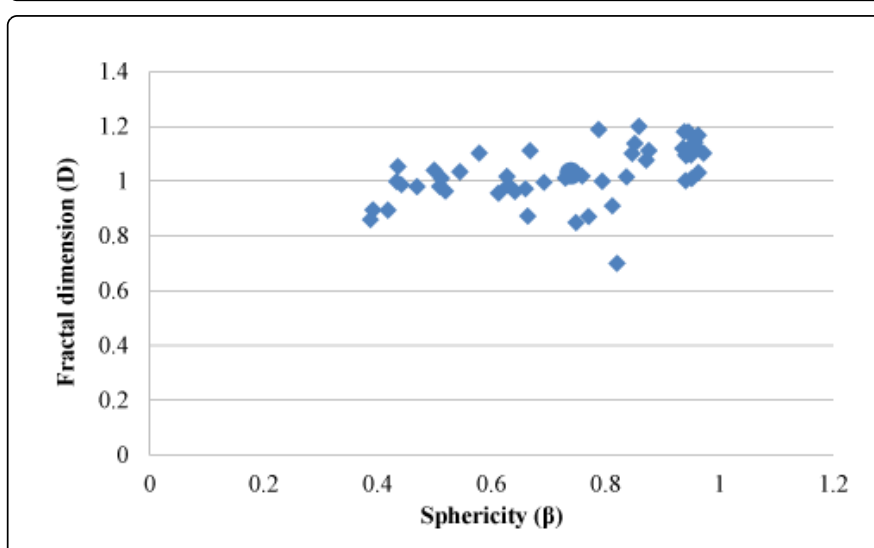

Figure 10: Platelet distribution map for recycled AlSi2.4Mg Alloy modified with $10 \mathrm{gr}$ of $\mathrm{Sb}$

The weighted average values were used to relate with the test results of tensile strength for all the specimens. Figure 12 shows the relationship between the weighted values of sphericity and the tensile strength (TS) for all the cast samples. Here, each data point represents 
a platelet in a sample. It appears that the as-cast sample has lower tensile strength and low sphericity while the samples modified with $\mathrm{Sb}$ have higher tensile strength and higher sphericities.

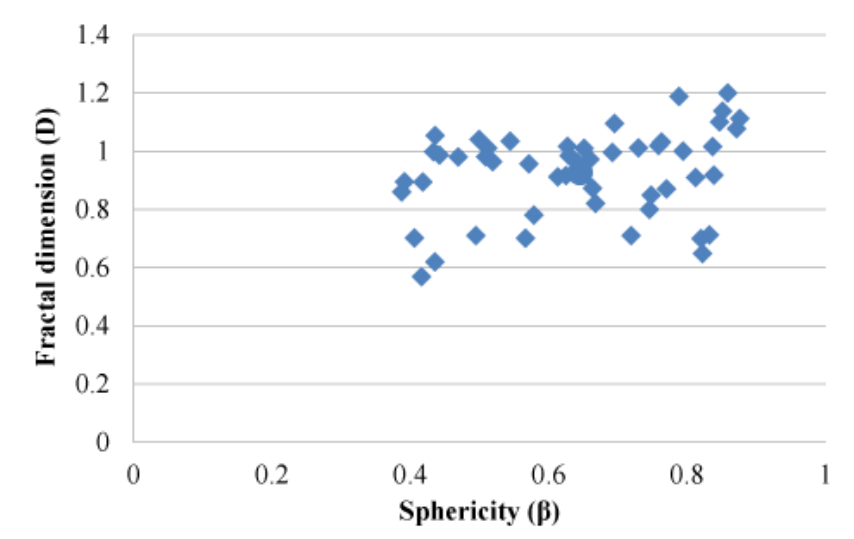

Figure 11: Platelet distribution map for recycled AlSi2.4Mg Alloy modified with 12 gr of $\mathrm{Sb}$

The platelet distribution maps have shown the reasons why the sample modified with $8 \mathrm{gr}$ addition of $\mathrm{Sb}$ has the highest value of tensile strength. This can be linked to the fact that there is little or no clustering in the sample modified with $8 \mathrm{gr}$ of $\mathrm{Sb}$ therefore making it difficult for the platelets to link one another leading to improvement in tensile strength. On the other hand, the formation of unstable intermetallic compound above 8 gr led to decrease in the mechanical properties of the material which become more pronounced at $12 \mathrm{gr}$ addition of $\mathrm{Sb}$, this is similar to the observation made by Manasijevic et al. [20].

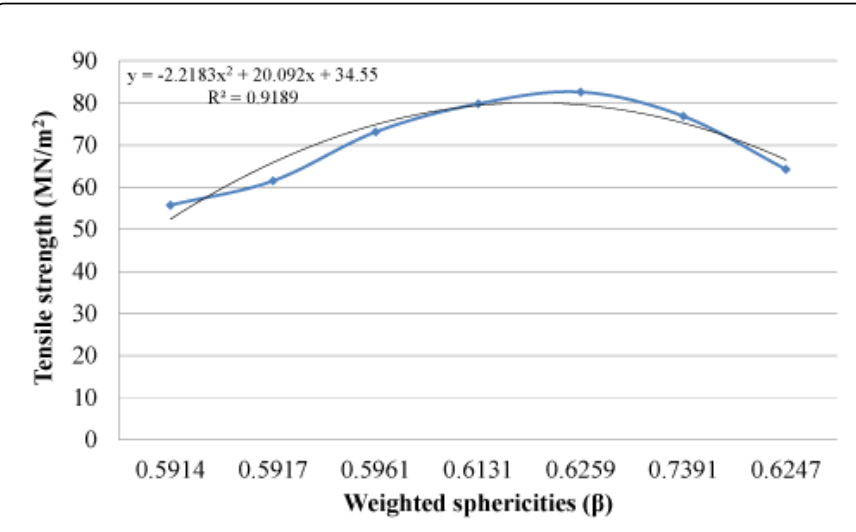

Figure 12: Relationship between weighted average sphericities and the tensile strength

Moreover, as sphericity increases, the tensile strength also increases indicating a transition from irregular shapes of the Si platelets to more regular domain. The graph which is represented by the empirical equation $y=-1.897 x^{2}+23.4 x-14.46$ shows that an optimum value of tensile strength is obtained at average sphericity of 0.6. After this point, further transition to regular shapes cause a decrease in tensile strength, but the rate of decrease is less than the rate of increase in the tensile strength before the optimum point. Thus, addition of $\mathrm{Sb}$ beyond 8 gr will lead to additional cost and a reduction in tensile strength.

\section{Conclusion}

From the platelet distribution map, it can be seen that each platelet in the as-cast alloy are bigger in size and clustered meaning that their morphology can act as seedbed for micro-crack initiation. On the other hand, addition of $\mathrm{Sb}$ to $\mathrm{AlSi} 2.4 \mathrm{Mg}$ alloy gave good morphological changes in Si platelets. The optimum amount of $\mathrm{Sb}$ needed for modification of $\mathrm{Si}$ platelets is $8 \mathrm{gr}$ with corresponding tensile strength of $82.59 \mathrm{MN} / \mathrm{m}^{2}$. This work has shown that addition of antimony as a modifier should not exceed $8 \mathrm{gr}$ for $150 \mathrm{gr}$ of the ingot of the recycled aluminum piston alloys. Hence, the quantitative estimation of the morphology of Si platelets such as their shapes, sizes and distribution can be a source of useful information. If such estimation is applied at the foundry floor to identify the cause of crack initiation, it is expected that likely failure in recycled cast Al-alloys will be substantially reduced.

\section{References}

1. Farkašová M, Tillová E, Chalupová M (2013) Modification of Al-Si-Cu cast alloy. FME Transactions 41: 210-215.

2. Hansen SC, Loper Jr. CR (2000) Effect of antimony on the phase equilibrium of binary Al-Si alloys. Calphad 24: 339-352.

3. Abdulwahab M, Madugu IA, Asuke F, Fayomi OSI, Ayeni FA (2013) Effect of thermal ageing treatment on the mechanical properties of antimony-modified A356.0-type Al-Si-Mg alloy. J Mater Environ Sci 4: 87-92.

4. Muñiz R, Flores A, Ortiz J, Rodríguez N, Martínez F, et al. (2013) Characterization by EBSD of antimony-calcium rich phases formed during purification of aluminum scrap. Journal of Wuhan University of Technology-Mater Sci Ed 28: 647-649.

5. Paraskevas D, Kellens K, Renaldi R, Dewulf W, Duflou JR (2013) Closed and Open Loop Recycling of Aluminium: A Life Cycle Assessment perspective. Proceedings of 11th Global Conference on Sustainable Manufacturing-Innovative Solutions, Berlin, Germany.

6. Alwan HA, al-Jubouri HAH, Saffar NLA (2013) Use of waste for the manufacture of Electric Power Transmission Wires. Int J Eng Technol 3: 906-913.

7. Bolden J, Abu-Lebdeh T, Fini E (2013) Utilization of recycled and waste materials in various construction applications. Am J Environ Sci 9: 14-24.

8. Fintová S, Konecná R, Nicoletto G (2010) Influence of Shrinkage Porosity on the Fatigue Behavior of Cast AlSi7Mg. Roznov pod Radhostem, Czech Republic, EU.

9. Hurtalová L, Tillová E, Chalupová M, Duriníková E (2012) Effect of Chemical Composition of Secondary Al-Si Cast Alloy on Intermetallic Phases. MTM 6: 11.

10. Kósa A, Gácsi Z, Dúl J (2012) Effects of Strontium on the Microstructure of Al-Si Casting Alloys. Materials Science and Engineering 37: 43-50.

11. Özer G, Burgucu S, Marsoğlu M (2012) A Study on the Recycling of Aluminium Alloy 7075 Scrap. Materials Testing 54: 175-178.

12. Hangai Y, Kitahara S (2008) Quantitative Evaluation of Porosity in Aluminum Die Castings by Fractal Analysis of Perimeter. Materials Transactions 49: 782-786.

13. Jha DK, Singh DS, Gupta S, Ray A (2012) Fractal analysis of crack initiation in polycrystalline alloys using surface interferometry. EPL 98: 44006.

14. Durowoju MO, Oladosu KO, Akintan AL (2013) Fractal Analysis of the Platelets in Al-Si Eutectic Cast Alloy. Int J Eng Sci Technol 5: 1111-1119.

15. Purenović J, Mitić VV, Kocić Lj, Pavlović V, Ranđelović M, et al. (2013) Intergranular area microalloyed aluminium-silicate ceramics fractal analysis. Science of Sintering 45: 117-126. 
16. Durowoju MO, Akintan AL (2013) Variation between Fractal Geometry and Mechanical Properties of Al Alloys under Different Heat Treatments. Int J Sci Adv Technol 3: 38-44.

17. Mandelbrot BB (1982) The Fractal Geometry of Nature. Henry Holt and Company, New York, USA.

18. Lu S, Hellawell A (1994) An application of fractal geometry to complex microstructures: Numerical characterization of graphite in cast irons. Acta Metallurgica et Materialia 42: 4035-4047.
19. Huang YJ, Lu SZ (2002) A Measurement of The Porosity in Aluminum Cast Alloys Using Fracatal Analysis. Proceeding of 2nd International Aluminum Casting Technology Symposium, ASME, Houston, USA.

20. Manasijevic S, Markovic S, Pavlovic ZA, Raic K, Radica R (2013) Effect of heat treatment on the microstructure and mechanical properties of piston alloys. Journal of Materials and Technology 47: 585-591. 